\title{
Deep Vein Thrombosis due to Oral Contraceptive use in a Young Female
}

\author{
Jaideep Malhotra, Ruchika Garg, Prabhat Agrawal
}

\section{ABSTRACT}

Use of combined oral contraceptive pill (COC) is associated with a three fold increase in venous thromboembolism (VTE) risk compared to nonuse. ${ }^{1}$ The absolute risk for deep vein thrombosis (DVT) in younger women without risk factor for VTE is extremely low.

We report here a case of thrombosis of both deep and superficial venous system following use of second generation COC for just 2 months.

Keywords: Deep vein thrombosis, Oral contraceptive pills, Venous thromboembolism.

How to cite this article: Malhotra J, Garg R, Agrawal P. Deep Vein Thrombosis due to Oral Contraceptive use in a Young Female. J South Asian Feder Obst Gynae 2013;5(3):161-162.

\section{Source of support: Nil}

Conflict of interest: None declared

\section{INTRODUCTION}

The baseline risk of venous thromboembolism is five per 100,000 person years. This risk increase to $15 / 100,000$ women/ year in women taking second-generation pills (Levonorgestrel), while it is 25 per 100,000 women/year in women taking third generation pills (Containing progestin's desogestrel and gestodene). ${ }^{2}$

Although it is rare, it can cause death in about 1 to $2 \%$ of all cases of VTE in women taking the pill. ${ }^{3}$

\section{CASE REPORT}

A 25 years old female presented in the out patient clinic with chief complaints of pain and swelling in right lower limb for the last 5 days. Two months before presentation she was started on COC (Levonorgestrel $0.15 \mathrm{mg}+$ Ethinyl estradiol $0.03 \mu \mathrm{g}$ ). There was no personal or family history suggestive of DVT, bleeding or clotting disorder. There was no history of recent trauma or extended bed rest. There was no previous surgical history or use of tobacco or alcohol. She was non-smoker. There were no signs of local or systemic infection. On examination her Body mass index (BMI) was $26 \mathrm{~kg} / \mathrm{m}^{2}$, Blood Pressure = 130/80 mm Hg. All peripheral pulses including femoral, popliteal and pedal pulses were normal. Right lower limb was swollen and hot compared to left, Homan's sign was positive. Her systemic examination was normal. Her hemogram including ESR, $\mathrm{C}$ reactive protein (CRP), renal function test, liver function test and chest X-ray were normal. LE cell, antinuclear antibody, antiphospholipid antibody and VDRL were negative. Antithrombin III and protein $\mathrm{C}$ and protein $\mathrm{S}$ activities were normal. Duplex ultrasound revealed superficial
(Fig. 1) and deep vein thrombosis. Thrombus was seen in common iliac (Fig. 2), femoral, popliteal and tibial vein. OCPs were stopped. She was started on Fondaparinux sodium for 7 days and warfarin was given for the next 6 months. International normalized ratio (INR) was maintained between two and three.

Gradually, the patient recovered clinically and after 1 month Doppler ultrasound also revealed increased flow. On follow-up, she had no evidence of recurrence.

\section{DISCUSSION}

COCs causes a significant increase in fibrinogen and vitamin $\mathrm{K}$-dependent coagulation factors, but there is also a significant increase in fibrinolysis which may balance any potential thrombotic risk in women without other risk factors for venous thromboemoblism. The risk appears to be related to the dose of estrogen. As the dose of estrogen has been reduced from $50 \mu \mathrm{g}$ ethinyl estradiol (EE) to $35 \mu \mathrm{g}$ the incidence of VTE has
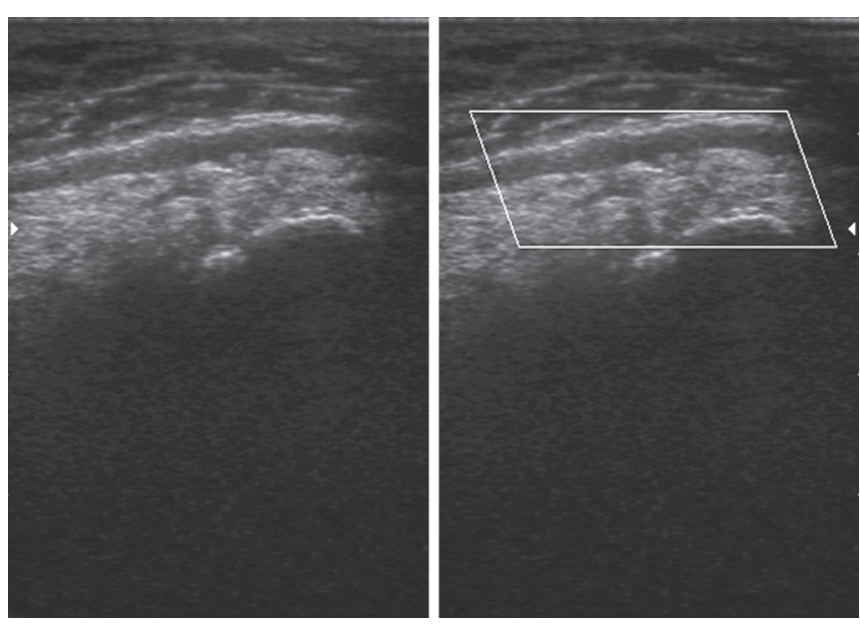

Fig. 1: Thrombosis of great saphenous vein
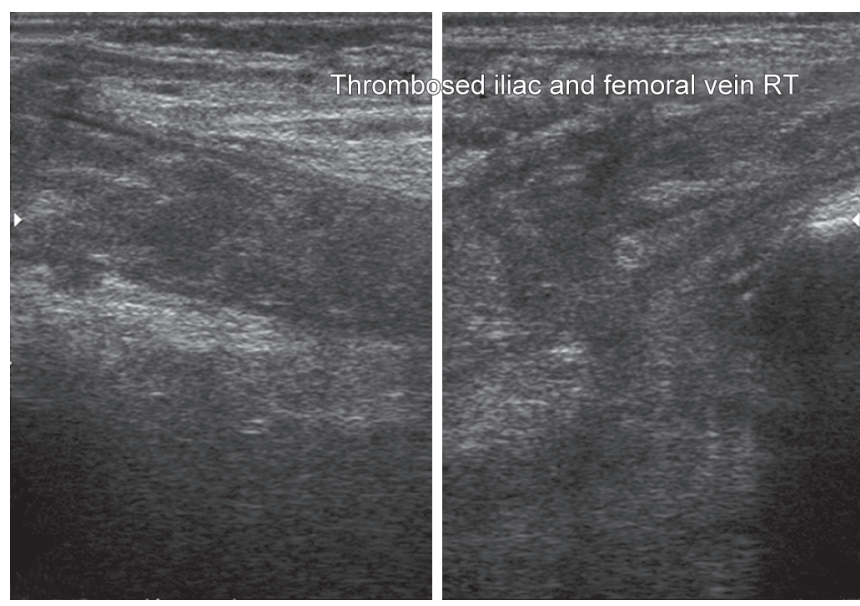

Fig. 2: Thrombosed iliac and femoral vein 
declined. ${ }^{7}$ Reducing the dose of estrogen to $20 \mu \mathrm{g}$ EE seems to reduce the risk of VTE further. ${ }^{3}$ Recent research has also shown the influence of type of progestin for increasing the risk of VTE. Risk is lowest for levonorgestrel and norethisterone, and relative risk is 1.5 to 2 for gestodene, desogestrel and norgestimate compared with levonorgestrel. Drosperinone and cyproterone acetate were found to have similar risks to desogestrel and gestodene (1.6-1.8 greater than with LNG). ${ }^{3}$

Both venous and arterial thrombosis are unrelated to duration of use or past use of COCs. ${ }^{5}$ The greatest risk of COC associated VTE occurs during the first year of use. ${ }^{6}$ Dulicek et al have described in their study of 400 women with thromboembolism associated with use of OCP that average duration of use was 45 months at the onset of thrombosis. But in our case DVT appeared in first 2 months of use of OCPs. ${ }^{8}$

In order to optimize the benefit risk balance of oral contraception, the search for a biological thrombophilia is essential in some cases such as in young women with a history of venous thromboembolic event or with family history of thrombosis at a relatively young age. ${ }^{4}$

The key points for the safe use of COCs are a full clinical, personal and family history in to evaluate risk factors for VTE and cardiovascular disease, along with the recording of blood pressure and body mass index prior to prescription of COCs. ${ }^{6}$

\section{REFERENCES}

1. Sehovic N, Smith KP. Risk of venous thromboembolism with drospirenone in combined oral contraceptive products (May). Ann Pharmacother 2010 Apr 6. (Epub ahead of print).

2. Mayer S. Department of health changes advise on 3rd generation pills. BMJ 1999 Apr 17;318(7190):1026.
3. Editorials. Oral contraceptive and venous thromboembolism. BMJ 2009;339:b3164.

4. Plu: Bureau G, Horellou MH, Gompel A, Conard. J Gynecol Obstet Fertil 2009 Apr;36(4):448-454.

5. Tanis BC, Rosendaal FR. Venous and arterial thrombosis during oral contraceptive use: risks and risk factors. Semin Vasc Med $2003 \mathrm{Feb} ; 3(1): 69-84$.

6. Martinez F, Avecilla A. Combined hormonal contraception and venous thromboembolism. Eur J Contracept Reprod Health Care 2007 June;12(2):97-106.

7. Murphy EH, Davis CM III, Arko FR. Oral contraceptive and deep vein thrombosis. Endovascular Today 58 Aug 2008.

8. Dulícek P, Malý J, Venous thromboembolism in young female while on oral contraceptives: high frequency of inherited thrombophilia and analysis of thrombotic events in $400 \mathrm{czech}$ women. Clin Appl Thromb Hemost 2009 Oct;15(5):567-573. Epub 2008 Dec 30.

\section{ABOUT THE AUTHORS}

\section{Jaideep Malhotra}

Consultant IVF Specialist, Department of Obsterics and Gynecology Malhotra Nursing and Maternity Home, Agra, Uttar Pradesh, India

\section{Ruchika Garg (Corresponding Author)}

Lecturer, Department of Obstetrics and Gynecology SN Medical College, Agra, Uttar Pradesh, India, e-mail: ruchikagargagra@gmail.com

\section{Prabhat Agrawal}

Lecturer, Department of Medicine, SN Medical College, Agra Uttar Pradesh, India 